\title{
Laparoscopic completion gastrectomy in elderly patients with remnant gastric cancer: a case series
}

\author{
Masaki Kaihara' ${ }^{1}$ Satoru Matsuda ${ }^{1,2^{*}}$, Eisuke Booka ${ }^{1}$, Fumitaka Saida', Jumpei Takashima', Hanako Kasai ${ }^{1}$, \\ Koki Mihara ${ }^{1}$, Atsushi Nagashima ${ }^{1,3}$ and Tomohisa Egawa ${ }^{1}$
}

\begin{abstract}
Background: Open completion gastrectomy (OCG) has been selected to treat remnant gastric cancer (RGC) due to severe adhesions and difficulty recognizing anatomical orientation after primary gastrectomy. In general, elderly individuals' physiological reserves gradually decrease. Moreover, elderly patients (EPs) often have multiple complicating factors (i.e., frailty and comorbidities), leading to more postoperative complications after abdominal surgery. Recently, several trials revealed the advantages of laparoscopic surgery for EPs with gastric cancer in early recovery. However, there are limited studies investigating the use of laparoscopic completion gastrectomy (LCG) for RGC in EPs. This study aims to assess the efficacy of LCG in EPs aged $\geq 70$ years. We compared the short- and longterm outcomes of LCG with those of OCG.
\end{abstract}

Case presentation: Twenty-one EPs who underwent completion gastrectomy for RGC between 2007 and 2017 were enrolled and classified into two groups according to the surgical approach, namely the LCG $(n=6)$ and OCG ( $n=15)$ groups. We adopted the G8 geriatric screening tool to comprehensively evaluate the EPs' physical, mental, and social functions. Patient characteristics, clinicopathological characteristics, surgical outcomes, and survival were retrospectively reviewed and compared between groups.

Results: There was no significant difference in the preoperative modified G8, indicating that the EPs' backgrounds between the groups were comparable. Of note, blood loss during surgery was significantly reduced in the LCG group [median (range); LCG, $50 \mathrm{ml}$ (20.0-65.0); OCG, $465 \mathrm{ml}$ (264.5-714.0); $p=0.002$ ]. The median number of retrieved lymph nodes in the LCG and OCG groups were 7 (range 4-10) versus 3 (range 1-6), respectively. There were no statistically significant differences in postoperative hospitalization, intake of solid food, and Clavien-Dindo grade $\geq \|$ postoperative complications. In patients with a history of gastrectomy for gastric cancer in the LCG group, operative time tended to be longer in patients who underwent D2 lymph node dissection as primary surgery.

Conclusions: LCG was comparable to OCG for the treatment of RGC in EPs with significantly reduced blood loss. While LCG should be selected with caution in patients who have undergone D2 lymph node dissection as primary surgery, it could be considered as a surgical procedure in EPs with RGC.

Keywords: Remnant gastric cancer, Laparoscopic completion gastrectomy, Elderly patients

\footnotetext{
* Correspondence: s.matsuda.a8@keio.jp

'Department of Surgery, Saiseikai Yokohamashi Tobu Hospital, 3-6-1,

Shimosueyoshi, Tsurumi-ku, Yokohama-shi, Kanagawa 230-8765, Japan

${ }^{2}$ Department of Surgery, Keio University School of Medicine, 35

Shinanomachi, Shinjuku-ku, Tokyo 160-8582, Japan

Full list of author information is available at the end of the article
} 


\section{Background}

In the Japan Clinical Oncology Group (JCOG) 0912 trial, laparoscopic surgery (LS) for treating early-stage gastric cancer was shown to be a feasible procedure in terms of adverse events and short-term clinical outcomes [1]. Currently, LS has been established as a standard treatment [2]. In addition, the LS safety profile in distal gastrectomy with D2 lymphadenectomy for advanced gastric cancer is comparable to that reported for open surgery (OS) regarding postoperative morbidity and mortality rates [3].

For remnant gastric cancer (RGC), the surgical resection is indicated in numerous cases [4] and open completion gastrectomy (OCG) is ordinarily selected due to severe adhesions and difficulty recognizing the anatomical orientation after primary gastrectomy. On the other hand, as LS has been developed for gastric cancer, there is increasing evidence that the laparoscopic completion gastrectomy (LCG) can be a therapeutic option for RGC [5]. Moreover, we conducted a study at Saiseikai Yokohamashi Tobu Hospital showing the safety and the efficacy of LCG [6].

Elderly peoples require special consideration due to the decline in physical, physiological, and social functions [7]. Thus, a careful and safe surgical approach in elderly patients (EPs) is required. Two meta-analyses revealed LS advantages for treating EPs with gastric cancer in terms of early recovery and fewer complications $[8,9]$. However, there are limited studies investigating the use of LS for the treatment of RGC in EPs.

In the present study, we reviewed RGC patients assigned to either the LCG or the OCG group over a 10 -year period. Evaluating short- and long-term outcome, we aim to assess the efficacy of LCG in treating EPs.

\section{Case presentation}

\section{Patients and methods}

We retrospectively reviewed 21 patients aged $\geq 70$ years who underwent completion gastrectomy for RGC between April 2007 and October 2017 at Saiseikai Yokohamashi Tobu Hospital. The patients were classified into two groups according to the surgical approach, namely the LCG $(n=6)$ and OCG $(n=15)$ groups. We adopted the G8 geriatric screening tool to comprehensively evaluate the EPs' physical, mental, and social functions [10]. Since the score for one question pertaining to the self-perception of health was not obtained, the total score was calculated based on the remaining seven questions. In all patients, the clinical stage was evaluated according to the Japanese Classification of Gastric Carcinoma [11]. Postoperative complications were categorized using the Clavien-Dindo classification (C-D) [12]. In this study, complications classified as C-D grade $\geq$ II were considered postoperative complications. Patient characteristics, clinicopathological characteristics, surgical outcome, and survival were retrospectively reviewed and compared between the LCG and the OCG groups.

Both surgical approaches were presented to the patients, and either OCG or LCG was selected based on their preferences and their surgeons' recommendations. All surgeries were performed by board-certified surgeons (Japan Surgical Society), and all LCG were performed by TE, who is a qualified surgeon according to the Endoscopic Surgical Skill Qualification System.

\section{Surgical procedures}

LCG and OCG with splenic preservation were conducted. Reconstruction was performed using the Roux-en-Y (R-Y) method. In LCG, patients under general anesthesia were placed in the reverse Trendelenburg position with the legs slightly apart. The surgeon stood on the patient's left side, with an assistant on the right and another assistant holding a laparoscope between the legs. An initial 12-mm trocar was inserted at the umbilicus through the open method. Reviewing the abdominal cavity, we checked whether there were adhesions to the abdominal wall. In cases with previous LS, other ports were placed at the previous port wound $(5 \mathrm{~mm}$ on the subcostal region and $12 \mathrm{~mm}$ on the abdomen bilaterally) (Fig. 1). A flexible electrolaparoscope was used, and the $\mathrm{CO}_{2}$ pressure was maintained at $10 \mathrm{mmHg}$.

The remnant stomach was completely mobilized by dissecting the adhesion between the remnant stomach and the left lateral segment of the liver, as well as the one between the remnant stomach and the pancreas. For patients in whom primary surgery was performed for benign disease, the supra pancreatic lymph nodes

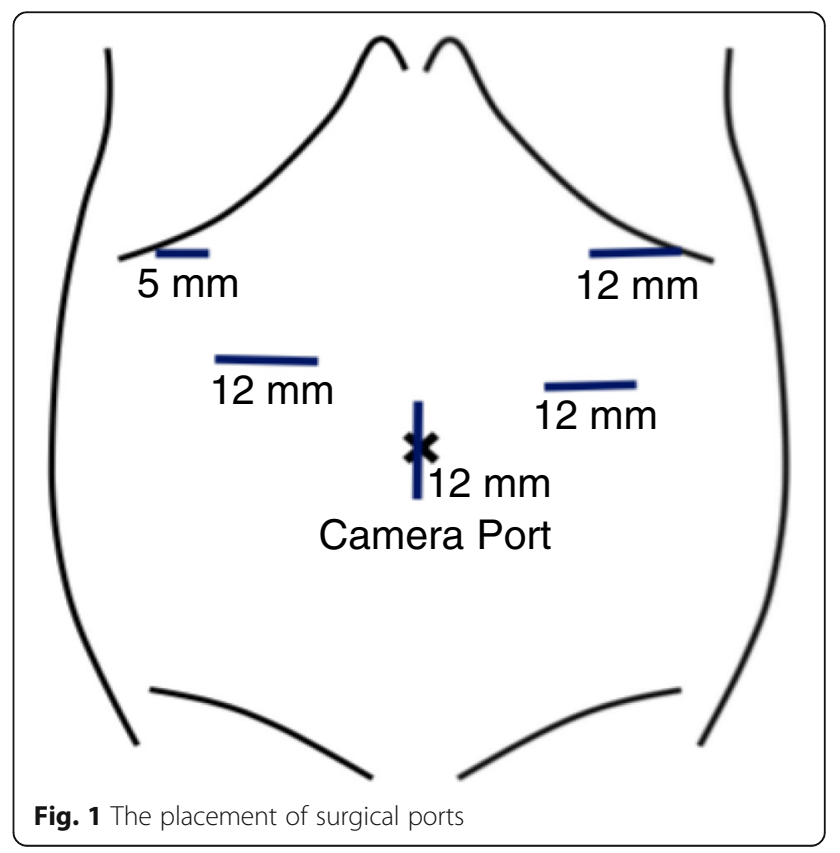


were resected in addition to those around the remnant stomach. The reconstruction was performed using the R-Y method through the pre-colon route. Esophagojejunostomy was performed using the overlap technique in the LCG group [13].

\section{Statistical analysis}

Statistical analysis was performed using $\mathrm{R}$ version 3.5.1 (The R Foundation for Statistical Computing, Vienna, Austria). Demographic and surgical data were compared between the LCG and OCG groups. Continuous variables were analyzed using the Mann-Whitney $U$ test. Categorical data were compared using Fisher's exact probability test or the chi-squared test. Patient survival was calculated using the Kaplan-Meier method, and the significance of differences between the curves was analyzed using the log-rank test. A $p<0.05$ denoted statistical significance in all analyses.

\section{Results}

\section{Preoperative evaluation using the G8 geriatric screening} tool

Using the G8 geriatric screening tool, we retrospectively evaluated the patients' physical, mental, and social conditions. The answers to the individual questions are provided in Table 1. Two patients had lost $>3 \mathrm{~kg}$ of weight in the OCG group, whereas those in the LCG group tended to show a lower body mass index without statistical significance. Overall, there was no significant difference in the individual scores, resulting in total scores of 12.5 and 13.0 for the LCG and OCG groups, respectively $(p=0.841)$.

\section{Preoperative patient characteristics}

Comparisons of preoperative patient characteristics between the two groups are shown in Table 2. The proportion of males and patients who underwent OS as initial gastrectomy were significantly higher in the OCG group ( $p=0.014$ and $p=0.022$, respectively). There were no differences between the two groups in terms of previous disease and reconstruction procedure. In addition, there was no significant difference in the time interval between the previous gastrectomy and the completion gastrectomy $(p=0.907)$.

\section{Pathological findings, surgical outcomes, and postoperative course}

In terms of surgical outcomes (Table 3), blood loss was significantly lower in the LCG group versus the OCG group [median (range); LCG, $50 \mathrm{ml}$ (20.0-65.0); OCG, $465 \mathrm{ml}$ (264.5-714.0); $p=0.002$ ]. There was no significant difference in operative time between the two groups ( $p=$ 0.791). Due to the severe adhesion between the abdominal wall and small intestine, the laparoscopic approach was converted to the open approach in one patient from the
Table 1 Preoperative evaluation using the G-8 geriatric screening tool

\begin{tabular}{|c|c|c|c|}
\hline Items (possible answers: score) & $\mathrm{LCG}, n=6$ & OCG,$n=15$ & $p$ \\
\hline $\begin{array}{l}\text { Decrease in food intake in the } \\
\text { past } 3 \text { months }\end{array}$ & & & 0.159 \\
\hline Severe: 0 & 0 & 0 & \\
\hline Moderate: 1 & 0 & $4(27 \%)$ & \\
\hline No decrease: 2 & $6(100 \%)$ & $11(73 \%)$ & \\
\hline Weight loss in the past 3 months & & & 0.347 \\
\hline$>3 \mathrm{~kg}: 0$ & 0 & $2(13 \%)$ & \\
\hline Does not know: 1 & 0 & 0 & \\
\hline Between 1 and $3 \mathrm{~kg}: 2$ & 0 & 0 & \\
\hline No weight loss: 3 & $6(100 \%)$ & $13(87 \%)$ & \\
\hline Mobility & & & 0.105 \\
\hline Bed or chair bound: 0 & 0 & 0 & \\
\hline $\begin{array}{l}\text { Able to get out of bed and } \\
\text { chair but does not go out: } 1\end{array}$ & $1(17 \%)$ & 0 & \\
\hline Goes out: 2 & $5(83 \%)$ & $15(100 \%)$ & \\
\hline Neuropsychological problems & & & 0.516 \\
\hline $\begin{array}{l}\text { Severe dementia or } \\
\text { depression: } 0\end{array}$ & 0 & 0 & \\
\hline $\begin{array}{l}\text { Mild dementia or } \\
\text { depression: } 1\end{array}$ & 0 & $1(7 \%)$ & \\
\hline No mental problems: 2 & $6(100 \%)$ & $14(93 \%)$ & \\
\hline Body mass index & & & 0.182 \\
\hline$<19: 0$ & $2(33 \%)$ & $1(7 \%)$ & \\
\hline 19-21: 1 & $2(33 \%)$ & $5(33 \%)$ & \\
\hline 21-23: 2 & 0 & $6(40 \%)$ & \\
\hline$>23: 3$ & $2(33 \%)$ & $3(20 \%)$ & \\
\hline $\begin{array}{l}\text { More than three prescribed } \\
\text { medications }\end{array}$ & & & 0.576 \\
\hline Yes: 0 & $2(33 \%)$ & $7(47 \%)$ & \\
\hline No: 1 & $4(67 \%)$ & $8(53 \%)$ & \\
\hline Self-perception of health & - & - & - \\
\hline \multicolumn{4}{|l|}{ Not as good: 0} \\
\hline \multicolumn{4}{|l|}{ Does not know: 0.5} \\
\hline \multicolumn{4}{|l|}{ As good: 1} \\
\hline \multicolumn{4}{|l|}{ Better: 2} \\
\hline Age & & & 0.125 \\
\hline$>85: 0$ & $1(17 \%)$ & 0 & \\
\hline 80-85: 1 & $2(33 \%)$ & $2(13 \%)$ & \\
\hline$<80: 2$ & $3(50 \%)$ & $13(87 \%)$ & \\
\hline Modified score (median, range) & $12.5,11.3-13.8$ & $13.0,12.0-13.5$ & 0.841 \\
\hline
\end{tabular}

LCG laparoscopic completion gastrectomy, OCG open completion gastrectomy

LCG group who had undergone open gastrectomy with Billroth-I reconstruction for gastric cancer as primary surgery. The median number of retrieved lymph nodes in the LCG group was 7 (range 4-10) versus 3 (range 1-6) in 
Table 2 Preoperative patient characteristics

\begin{tabular}{|c|c|c|c|}
\hline & $\begin{array}{l}\text { LCG } \\
n=6\end{array}$ & $\begin{array}{l}\text { OCG } \\
n=15\end{array}$ & $p$ \\
\hline Sex & & & $\overline{0.014}$ \\
\hline Male & $2(33 \%)$ & $13(87 \%)$ & \\
\hline Female & $4(67 \%)$ & $2(13 \%)$ & \\
\hline ASA-PS class & & & 0.526 \\
\hline । & $4(67 \%)$ & $8(53 \%)$ & \\
\hline$\|$ & $1(17 \%)$ & $1(7 \%)$ & \\
\hline III & $1(17 \%)$ & $6(40 \%)$ & \\
\hline IV & 0 & 0 & \\
\hline V & 0 & 0 & \\
\hline ECOG-PS & & & 0.105 \\
\hline 0 & $1(17 \%)$ & 0 & \\
\hline 1 & $5(83 \%)$ & $15(100 \%)$ & \\
\hline 2 & 0 & 0 & \\
\hline 3 & 0 & 0 & \\
\hline Original disease & & & 0.291 \\
\hline Malignant & $4(67 \%)$ & $13(87 \%)$ & \\
\hline Benign & $2(33 \%)$ & $2(13 \%)$ & \\
\hline Previous approach & & & 0.022 \\
\hline Open & $3(50 \%)$ & 14 (93\%) & \\
\hline Laparoscopic & $3(50 \%)$ & $1(7 \%)$ & \\
\hline Previous reconstruction & & & 0.844 \\
\hline$B-1$ & $4(67 \%)$ & $8(53 \%)$ & \\
\hline B-II & $1(17 \%)$ & $4(27 \%)$ & \\
\hline$R-Y$ & $1(17 \%)$ & $3(20 \%)$ & \\
\hline Time interval (years; median, range) & $15.5,2.3-37.8$ & $7.0,3.5-28.0$ & 0.907 \\
\hline
\end{tabular}

the OCG group ( $p=0.171)$. The LCG and OCG did not differ with respect to the distribution of TNM stages. Furthermore, there were no statistically significant differences in postoperative hospitalization ( $p=0.410$ ), intake of solid food ( $p=0.867)$, and the occurrence of C-D grade $\geq$ II postoperative complications $(p=0.477)$. Thirty days after surgery, there was no reported perioperative mortality in either group.

\section{Survival after completion gastrectomy}

In this study, the median follow-up period was 21 months, and the 5-year overall survival rate was $80.0 \%$ versus $60.6 \%$ in the LCG and OCG groups, respectively $(p=0.683$, Fig. 2$)$. Of the six deaths which occurred during the follow-up period, five were attributed to gastric cancer recurrence (one and four deaths, respectively). The remaining death was attributed to other diseases.
Table 3 Pathological findings, surgical outcomes, and postoperative course

\begin{tabular}{llll}
\hline & LCG & OCG & $p$ \\
& $n=6$ & $n=15$ & \\
\hline $\begin{array}{l}\text { Operative time } \\
\text { (min; median, range) }\end{array}$ & $310.5,249.5-337.8$ & $263.0,241.5-325.0$ & 0.791 \\
$\begin{array}{l}\text { Blood loss } \\
\text { (ml; median, range) }\end{array}$ & $50,20.0-65.0$ & $465,264.5-714.0$ & 0.002 \\
Open conversion, $n$ (\%) & $1(17 \%)$ & 0 & 0.105 \\
$\begin{array}{l}\text { Number of retrieved } \\
\text { LNs (median, range) }\end{array}$ & $7,4-10$ & $3,1-6$ & 0.171 \\
pT & & & 0.869 \\
T1 & $2(33 \%)$ & $5(33 \%)$ & \\
T2 & 0 & 0 & \\
T3 & $1(17 \%)$ & $4(26 \%)$ & \\
T4 & $3(50 \%)$ & $6(40 \%)$ & \\
pN & & $13(87 \%)$ & \\
N0 & $6(100 \%)$ & $1(7 \%)$ & \\
N1 & 0 & $1(7 \%)$ & 0.347 \\
N2 & 0 & 0 & \\
N3 & 0 & & \\
pM & $6(10 \% 2$ & \\
\hline
\end{tabular}

M0
p1
pStage

$\begin{array}{ll}6(100 \%) & 13(87 \%) \\ 0 & 2(13 \%)\end{array}$

IA

IB

IIA

$\| B$

IIIA

IIIB

IIIC

IV

Postoperative

hospitalization

(days; median, range)

Intake of solid food

(days; median, range)

Postoperative

complication

(C-D grade $\geq$ II)

Mortality within

30 days

after surgery

$\begin{array}{ll}2(33 \%) & 5(33 \%) \\ 0 & 0 \\ 117 \%) & 3(20 \%) \\ 0 & 0 \\ 3(50 \%) & 3(20 \%) \\ 0 & 0 \\ 0 & 2(13 \%) \\ 0 & 2(13 \%) \\ 9,7.3-13.8 & 9.8 .5-17.5\end{array}$

LCG laparoscopic completion gastrectomy, OCG open completion gastrectomy, $L N$ lymph node, $C-D$ Clavien-Dindo

\section{Comparison of the modified G8 geriatric screening tool score in patients with or without postoperative complications}

We evaluated the correlation between the modified G8 geriatric screening tool score and the occurrence of 


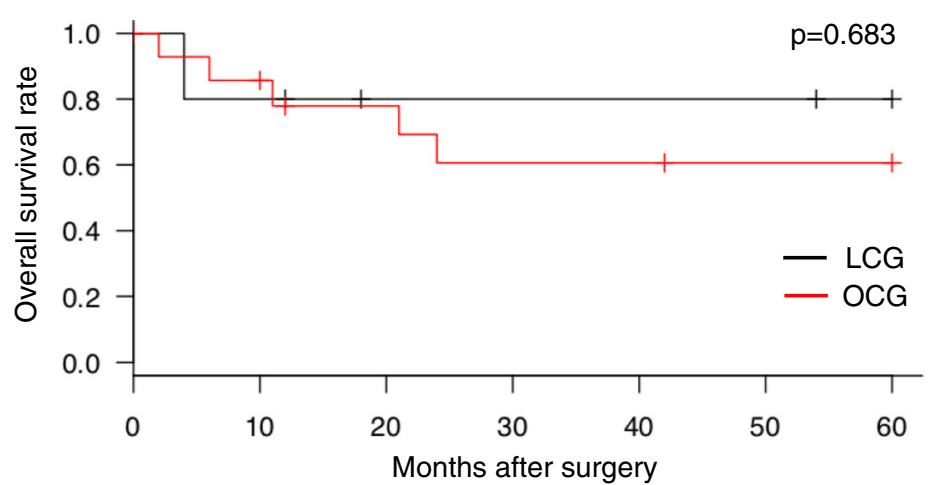

Number at risk

$\begin{array}{lccccccc}\text { LCG } & 6 & 4 & 2 & 2 & 2 & 2 & 1 \\ \text { OCG } & 15 & 12 & 9 & 7 & 7 & 5 & 5\end{array}$

Fig. 2 Overall survival. There was no significant difference in overall survival between the LCG and OCG groups. LCG laparoscopic completion gastrectomy, OCG open completion gastrectomy

postoperative complications. The analysis showed that there was no significant difference in the modified G8 geriatric screening tool scores between patients with and without postoperative complications $(p=0.654$, Table 4$)$.

\section{Comparison of the postoperative modified G8 geriatric screening tool score among the patients who did not exhibit postoperative recurrence}

We also evaluated the role of G8 geriatric screening score 1 year after surgery. Based on the review of the clinical records, we could evaluate the scores of nine patients, including three and six patients in the LCG and OCG groups, respectively, among the 17 patients who did not exhibit postoperative recurrence. We found that there were no significant differences in any of the factors including the total score [median (range); LCG, 8.0 (7.58.5); OCG, 10.5 (8.3-12.8); $p=0.362$ ].

\section{Surgical outcome in LCG patients with a history of gastrectomy for gastric cancer as primary surgery} In the LCG group, two of the four patients with a history of gastrectomy for gastric cancer underwent D2 lymph node dissection as primary surgery. As shown in Table 5, operative time tended to be longer in patients with D2 gastrectomy [median (range); D2, $352.0 \mathrm{~min}$ (349.0355.0); D1 or $\mathrm{D} 1+, 251.8 \mathrm{~min}(271.5-292.3) ; p=0.333]$.

Table 4 Comparison of the modified G8 geriatric screening tool scores in patients with or without postoperative complications

\begin{tabular}{llll}
\hline & $\begin{array}{l}\text { Postoperative } \\
\text { complication (C-D grade } \geq I I)\end{array}$ & \\
\cline { 2 - 3 } & Present $(n=8)$ & None $(n=13)$ & \\
\hline $\begin{array}{l}\text { Modified G8 geriatric screening } \\
\text { tool score (median, range) }\end{array}$ & $13,11.0-14.0$ & $13,12.8-13.3$ & 0.654 \\
\hline$C-D$ Clavien-Dindo & & & \\
\hline
\end{tabular}

\section{Discussion}

There was no significant difference in the preoperative modified G8 geriatric screening tool score, indicating that the EPs' backgrounds in each group were comparable. Blood loss during surgery was significantly reduced in the LCG group. In addition, there was no significant difference in oncological outcomes (e.g., the number of dissected lymph nodes) and prognosis. Overall, we demonstrated that LCG was shown to be applicable for treating EPs aged $\geq 70$ years.

A standard surgical treatment for RGC has not been established. In terms of the indication of splenectomy, total gastrectomy without splenectomy was shown to be non-inferior to the one without splenectomy in treating proximal advanced gastric cancer without the lesions on the greater curvature in the JCOG 0110 trial [14].

Table 5 Surgical outcomes in patients with the history of gastrectomy for gastric cancer as primary surgery in the LCG group

\begin{tabular}{|c|c|c|c|}
\hline $\begin{array}{l}\text { Lymphadenectomy } \\
\text { for primary surgery }\end{array}$ & $\begin{array}{l}\text { D2 } \\
(n=2)\end{array}$ & $\begin{array}{l}\mathrm{D} 1+/ \mathrm{D} 1 \\
(n=2)\end{array}$ & $p$ \\
\hline $\begin{array}{l}\text { Operative time } \\
\text { (min; median, range) }\end{array}$ & $352.0,349.0-355.0$ & $271.5,250.8-292.3$ & 0.333 \\
\hline $\begin{array}{l}\text { Blood loss } \\
\text { (ml; median, range) }\end{array}$ & $30,20-40$ & $190,130-250$ & 0.333 \\
\hline Open conversion, $n$ (\%) & 0 & $1(50 \%)$ & 0.248 \\
\hline $\begin{array}{l}\text { Postoperative } \\
\text { hospitalization } \\
\text { (days; median, range) }\end{array}$ & $9,8.5-9.5$ & $12,9.5-14.5$ & 1 \\
\hline $\begin{array}{l}\text { Intake of solid food } \\
\text { (days; median, range) }\end{array}$ & $4.0,4.0-4.0$ & $2.5,2.4-2.8$ & 0.221 \\
\hline $\begin{array}{l}\text { Postoperative } \\
\text { complication } \\
\text { (C-D grade } \geq \text { II) }\end{array}$ & $1(50 \%)$ & 0 & 0.248 \\
\hline $\begin{array}{l}\text { Mortality within } 30 \text { days } \\
\text { after surgery }\end{array}$ & 0 & 0 & - \\
\hline
\end{tabular}


However, because the lymphatic network is altered following primary surgery for RGC [15], the results of the JCOG 0110 trial are not applicable to treating RGC. Moreover, primary gastrectomy may influence completion gastrectomy, including severe adhesion development. Therefore, OCG has been preferable for treating RGC. The present study was consistent with this paradigm; OCG was frequently selected for patients who had undergone OS as primary surgery (Table 2).

Ohira recommended endoscopic surveillance after distal gastrectomy and detection RGC at an early stage. Moreover, the minimally invasive approach of endoscopic submucosal dissection and LCG may provide patients with an improved quality of life [4]. Currently, five studies comparing LCG and OCG in RGC patients have been reported [5, 16-19]. These studies have shown LCG is safe and effective for treating RGC, including reduced blood loss, increased number of dissected lymph nodes, shorter time to first flatus, and lower complication rate. Consistent with these results, we recently reported the advantages of LCG over OCG [6].

Elderly peoples' physiological reserves gradually decrease. Moreover, elderly peoples' cases are characterized by multiple complicating factors such as frailty and comorbidities [7]. Consequently, EPs experience more postoperative complications after abdominal surgery [20]. Therefore, minimally invasive and enhanced recovery approaches are warranted for treating EPs. In the current analysis, LCG was associated with reduced blood loss, versus OCG, without extending operative time. This finding demonstrated the favorable safety profile in LCG. Furthermore, there was no significant difference in oncological outcomes and prognosis between the LCG and OCG groups. On the other hand, in the LCG group, the operation time tended to be longer in patients who had D2 lymph node dissection for gastric cancer as primary surgery. Especially for elderly patients, the physiopathological implications of laparoscopy including prolonged operation time should be carefully considered [21]. Therefore, LCG needs to be cautiously selected in patients who underwent D2 lymph node dissection for gastric cancer as primary surgery.

The present study was limited to retrospective assessments. To minimize bias in patient recruitment, we reviewed consecutive EPs who underwent completion gastrectomy at Saiseikai Yokohamashi Tobu Hospital. Another limitation of this study is that the surgical approach was selected based on patient preference and surgeons' recommendations. However, the retrospective evaluation, using the modified G8 geriatric screening tool score, confirmed no significant differences between the two groups (Table 1), indicating they were comparable in terms of vulnerability.

\section{Conclusions}

LCG was shown to be comparable to OCG for treating RGC in patients aged $\geq 70$ years. Furthermore, blood loss during surgery was significantly reduced in LCG versus OCG. While LCG should be selected with caution in patients who have undergone D2 lymph node dissection as primary surgery, it could be considered as a surgical procedure in EPs with RGC.

\section{Abbreviations}

C-D: Clavien-Dindo; EPs: Elderly patients; JCOG: Japan Clinical Oncology Group; LCG: Laparoscopic completion gastrectomy; LS: Laparoscopic surgery; OCG: Open completion gastrectomy; OS: Open surgery; RGC: Remnant gastric cancer; R-Y: Roux-en-Y

\section{Funding}

We declare that each author received no funding for this study.

Availability of data and materials

The datasets supporting the conclusions of this article are included within the article and its additional files.

\section{Authors' contributions}

MK and SM drafted the manuscript. SM participated in treating the patients and revised the manuscript. SM, EB, KM, AN, and TE performed the surgery. FS, HK, and JT participated in the surgery and postoperative management. All authors read and approved the final manuscript.

\section{Ethics approval and consent to participate}

All procedures were in accordance with the ethical standards of the responsible committees on human experimentation (institutional and national).

\section{Competing interests}

The authors declare that they have no competing interests.

\section{Publisher's Note}

Springer Nature remains neutral with regard to jurisdictional claims in published maps and institutional affiliations.

\section{Author details}

'Department of Surgery, Saiseikai Yokohamashi Tobu Hospital, 3-6-1, Shimosueyoshi, Tsurumi-ku, Yokohama-shi, Kanagawa 230-8765, Japan. ${ }^{2}$ Department of Surgery, Keio University School of Medicine, 35

Shinanomachi, Shinjuku-ku, Tokyo 160-8582, Japan. ${ }^{3}$ Department of Surgery, Saiseikai Kanagawaken Hospital, 6-6, Tomiya-chou, Kanagawa-ku,

Yokohama-shi, Kanagawa 221-0821, Japan.

Received: 5 November 2018 Accepted: 21 March 2019

Published online: 17 April 2019

\section{References}

1. Katai H, Mizusawa J, Katayama H, Takagi M, Yoshikawa T, Fukagawa T, et al. Short-term surgical outcomes from a phase III study of laparoscopy-assisted versus open distal gastrectomy with nodal dissection for clinical stage IA/IB gastric cancer: Japan Clinical Oncology Group Study JCOG0912. Gastric Cancer. 2017;20:699-708

2. Japanese Gastric Cancer A. Japanese gastric cancer treatment guidelines 2014 (ver. 4). Gastric Cancer. 2017;20:1-19.

3. Hu Y, Huang C, Sun Y, Su X, Cao H, Hu J, et al. Morbidity and mortality of laparoscopic versus open D2 distal gastrectomy for advanced gastric cancer: a randomized controlled trial. J Clin Oncol. 2016;34:1350-7.

4. Ohira M, Toyokawa T, Sakurai K, Kubo N, Tanaka H, Muguruma K, et al. Current status in remnant gastric cancer after distal gastrectomy. World J Gastroenterol. 2016:22:2424-33.

5. Tsunoda S, Okabe H, Tanaka E, Hisamori S, Harigai M, Murakami K, et al. Laparoscopic gastrectomy for remnant gastric cancer: a comprehensive review and case series. Gastric Cancer. 2016;19:287-92. 
6. Booka E, Kaihara M, Mihara K, Nishiya S, Handa K, Ito Y, et al. Laparoscopic total gastrectomy for remnant gastric cancer: a single-institution experience. Asian J Endosc Surg. 2018.

7. Evers BM, Townsend CM Jr, Thompson JC. Organ physiology of aging. Surg Clin North Am. 1994;74:23-39.

8. Wang JF, Zhang SZ, Zhang NY, Wu ZY, Feng JY, Ying LP, et al. Laparoscopic gastrectomy versus open gastrectomy for elderly patients with gastric cancer: a systematic review and meta-analysis. World J Surg Oncol. 2016;14:90.

9. Zong L, Wu A, Wang W, Deng J, Aikou S, Yamashita H, et al. Feasibility of laparoscopic gastrectomy for elderly gastric cancer patients: meta-analysis of non-randomized controlled studies. Oncotarget. 2017:8:51878-87.

10. Bellera CA, Rainfray M, Mathoulin-Pelissier S, Mertens C, Delva F, Fonck M, et al. Screening older cancer patients: first evaluation of the G-8 geriatric screening tool. Ann Oncol. 2012;23:2166-72.

11. Japanese classification of gastric carcinoma: 3rd English edition. Gastric Cancer. 2011;14:101-12.

12. Dindo D, Demartines N, Clavien PA. Classification of surgical complications: a new proposal with evaluation in a cohort of 6336 patients and results of a survey. Ann Surg. 2004;240:205-13.

13. Morimoto M, Kitagami H, Hayakawa T, Tanaka M, Matsuo Y, Takeyama H. The overlap method is a safe and feasible for esophagojejunostomy after laparoscopic-assisted total gastrectomy. World J Surg Oncol. 2014;12:392.

14. Sano T, Sasako M, Mizusawa J, Yamamoto S, Katai H, Yoshikawa T, et al. Randomized controlled trial to evaluate splenectomy in total gastrectomy for proximal gastric carcinoma. Ann Surg. 2017;265:277-83.

15. Son SY, Kong SH, Ahn HS, Park YS, Ahn SH, Suh YS, et al. The value of N staging with the positive lymph node ratio, and splenectomy, for remnant gastric cancer: a multicenter retrospective study. J Surg Oncol. 2017;116:884-93.

16. Son SY, Lee CM, Jung DH, Lee JH, Ahn SH, Park DJ, et al. Laparoscopic completion total gastrectomy for remnant gastric cancer: a single-institution experience. Gastric Cancer. 2015;18:177-82.

17. Kim HS, Kim BS, Lee IS, Lee S, Yook JH, Kim BS. Laparoscopic gastrectomy in patients with previous gastrectomy for gastric cancer: a report of 17 cases. Surg Laparosc Endosc Percutan Tech. 2014;24:177-82

18. Kwon IG, Cho I, Guner A, Kim HI, Noh SH, Hyung WJ. Minimally invasive surgen as a treatment option for gastric cancer in the elderly: comparison with open surgery for patients 80 years and older. Surg Endosc. 2015;29:2321-30.

19. Nagai E, Nakata K, Ohuchida K, Miyasaka Y, Shimizu S, Tanaka M. Laparoscopic total gastrectomy for remnant gastric cancer: feasibility study. Surg Endosc. 2014;28:289-96.

20. Polanczyk CA, Marcantonio E, Goldman L, Rohde LE, Orav J, Mangione CM, et al. Impact of age on perioperative complications and length of stay in patients undergoing noncardiac surgery. Ann Intern Med. 2001;134:637-43.

21. Caglia P, Tracia A, Buffone A, Amodeo L, Tracia L, Amodeo C, et al. Physiopathology and clinical considerations of laparoscopic surgery in the elderly. Int J Surg. 2016;33(Suppl 1):S97-S102.

\section{Submit your manuscript to a SpringerOpen ${ }^{\circ}$ journal and benefit from:}

- Convenient online submission

- Rigorous peer review

- Open access: articles freely available online

- High visibility within the field

- Retaining the copyright to your article

Submit your next manuscript at $\boldsymbol{\nabla}$ springeropen.com 